\title{
Training of Electrical Engineers
}

$A^{T}$ $T$ the International Congress of Electricians held in Paris last July, interesting papers were read by various authors describing the training given in their countries to young men desirous of qualifying for the higher posts in the electrical engineering profession. It appears that, as a rule, the degree of B.Sc. in engineering, or its equivalent, is given after going through a three or four years' course in a technical school or college. It is impossible in the workshops of a college to give a student that insight into methods of management and actual operating that can only be obtained in works offering machinery or apparatus for sale. Hence engineering graduates or those possessing recognised diplomas have to undergo a special apprenticeship course in works, railways, power or distributing stations or with communication companies in addition to their academic training.

These apprenticeship courses are usually at least a year in length. It is highly advisable that there should be a close connexion between works and college staff, to whom most of the outgoing students have to look for advice as to the course they should follow. There is naturally a close connexion between many works and engineering colleges. The supervisors of the apprentices make their own choice and are not necessarily impressed by the academic qualifications of the young men they interview. They have to choose men whom they think will qualify rapidly for staff posts. Large companies who take a number of higher apprentices every year take only a limited number from any one country or from any one engineering college. Trade considerations in Great Britain and other countries make it advisable to take overseas students and foreigners. Several of these firms pay their graduate apprentices, generally called 'student apprentices', a weekly wage varying from 108. to 508 ., but some ask for a premium which is generally more than paid back by a weekly wage. This appreciably lightens the present somewhat onerous burden of the cost of living.

Most of the papers read at the Paris meeting dealt with the syllabuses of training colleges for the early part of the engineering training of students. It seems generally recognised that in the present economic conditions throughout the world and the very varied requirements of engineers in the different branches of the industry, it is necessary that the syllabus should not be overburdened with subjects. In Norway it includes architecture, political economy and finance. In Sweden national and political economy, technical hygiene and the building of edifices are taught. In Poland special stress is laid on methods of electrifying the country with a view to its future prosperity. In Italy, radio technology is in the front rank. It has been introduced into the programme of every industrial school. In the University of Bologna there is a two years postgraduate course for radio engineers. The degree of Ph.D. is awarded for physics and for mathematical physics. Special importance is attached to photoelectricity, television and the technique of radiotelegraphy and telephony. In Spain and many other countries stress is laid on long distance communication by telephony through wires and through space. Technical teachers everywhere are fully aware of the importance of the rapid and spectacular advances in methods of communication between dis- tant stations which have been made during the last few years.

An interesting paper on electrical education in the United States was communicated by Prof. A. E. Kennelly. He divides training institutions into two groups, the collegiate group and the industrial group. The first contains universities and technical institutes of university rank; the second includes the research and training schools of industrial organisations, technical institutes, and professional, commercial, and correspondence schools. Actually there are 150 schools of collegiate type in the United States. These give full instruction in electrotechnics. In addition, there are 750 other schools which give partial courses in the subjects connected with electrical engineering. The complete electrotechnical course usually lasts four years. During the last two years of the course, students can specialise in transmission and distribution of energy, electric traction or electrical communication, but no two engineering colleges in the United States have identical programmes. In 1893, a society was founded for the advancement of technical knowledge. It has now 2,250 members, practically all of whom are professors or teachers in technical schools. Their judgments and decisions influence greatly the nature of the syllabus adopted by a college.

A certain number of American colleges give 'sandwich' courses of training, half the time of the students being spent in college and the other half in works. The student spends a certain number of weeks in works and a certain number in college alternately, the length of the cycle varying between two weeks and a year. For students who wish to take up 'heavy' engineering, this system has advantages. The practical work shows how important theory is and hence students pay closer attention to theoretical work. Some of the large colleges have a regular college course for four years for some of their students and simultaneously a sandwich course for others. One of the advantages is that the college can take more pupils and thus the overhead charges are reduced. There is a great variety of colleges of all kinds in America. Prof. Kennelly thinks that it would be a calamity not only for the United States but also for the world if any of these colleges cease to exist. The disappearance of a good school, whatever its type, may mean that those students who had intended to enter it must either go to some other college which is not so attractive to them or else seek to acquire their scientific knowledge by experience and private study, a method sometimes successful but more often leading to a great waste of energy.

Prof. C. L. Fortescue read a useful paper on the education of electrical engineers in Great Britain. Those students who intend to qualify fully as engineers in Great Britain usually leave their secondary or public school at the age of eighteen years, spend three or four years at a university or technical college and finish up with two years as a 'student apprentice' in works, power stations or railways. It will be seen that the training is an expensive one as during the five or six years the student is not selfsupporting.

In Great Britain, the Institution of Electrical Engineers looks after the interests and maintains the standard of the profession as a whole. It divides 
young electricians into two groups, students and graduates. The students of approved colleges and apprentices and assistants in engineering works can become 'students'. When a student has passed certain qualifying examinations and has attained the age of twenty-one years, he can be elected a graduate. A graduate, however, is not a 'chartered electrical engineer'. This status can only be attained after his training and experience exceeds seven years, two of which must have been in a position of superior responsibility in the profession. He has to send in an election form signed by five members and giving a complete account of his training and experience, which is scrutinised by an election committee. $\mathrm{He}$ must also be twenty-six years of age. When he fulfils all these somewhat onerous conditions, he is elected an associate of the Institution, and can call himself a chartered electrical engineer.

It will be noticed that there is a discontinuity in the training of an electrical engineer, namely, the gap between the university or technical college and works. Most students have no connexion with engineering and so have to make their own arrangements with manufacturing firms. Naturally, they want to go to the best-known firms, but it generally happens that these firms have already all the student apprentices they want. Hence they have to try to get into works about which they know nothing.

This has led to the adoption by a few colleges of the 'sandwich' system of training. The best-known of these colleges is Faraday House, London, which was founded more than forty years ago and now has about four hundred students. The course lasts for four years. The first year is a purely collegiate course in general engineering. During the second year the student is apprenticed under supervision to a mechanical engineering works either in Great Britain or abroad, the college making all the arrangements for him. The college is affiliated with 170 works and railways in Great Britain and abroad, for teaching purposes. Advanced theoretical training is given in college during the third year, and for the final year the students go to electrical manufacturing works and power stations throughout the country and to railways, and communication companies, etc. Those who have passed successfully through the course, several of whom also take the London B.Sc. (Engineering), receive the diploma which enables them to become graduates of the Institution of Electrical Engineers without further examination. The advantage of the system is that the student is under the same supervision throughout his course.

The recent extension of research laboratories in connexion with works has led to a limited demand for men who have done post graduate research work in university laboratories. These men usually write theses which help them to get the higher degrees of M.Sc., Ph.D. and D.Sc. Research laboratories also take young graduates whom they train specially in their own methods of research so as to qualify them for posts on their staff.

A.R.

\section{Solid Solutions and Liquid Mixtures}

\section{$\mathrm{T}$} $\mathrm{E}$ discussion arranged in Section $\mathrm{B}$ (Chemistry) on Sept. 6 at the York meeting of the British Association, was finally divided into two parts as it was agreed that the differences between solid solutions and liquid mixtures were too great for the subjects to be covered usefully in a single discussion. Prof. C. H. Desch in his paper on re-arrangements in the solid state referred to the importance of solid solu. tions in metallurgy and said that systems in which a series of solid solutions, stable at high temperatures, resolves itself into two or more phases on cooling are of frequent occurrence. Such systems are of two types. In the first, and most usual, the change takes the form of the separation of a new phase from solution in the same manner as the crystallisation of a salt from water. A solubility curve can be drawn and eutectoid structures similar to the eutectics produced from liquid solutions are produced. Familiar examples are the iron-carbon and ironnickel systems, and analysis of the constituents shows that a definite migration of nickel has taken place in the solid phase. In the second type of re-arrangement which has been observed in recent years, a solid solution homogeneous at high temperatures and having the solute atoms statistically distributed throughout its lattice assumes a new arrangement on cooling through a certain point, the solute atoms taking up regular positions and so forming a super-lattice. The change is reversed on heating. A typical example is furnished by the gold-copper alloys. The equilibrium is attained very quickly and the change can be followed by electrical resistance tests. Magnesium-cadmium alloys give a similar series and the changes are at present largely unexplained although the number of such systems may be considerable.
The discussion on mixed liquids was opened by Prof. Irvine Masson who indicated that its scope is limited to mixtures of non-electrolytic fluids. The main chemical interest in such liquids lies in the formation of inter-molecular compounds but Prof. Masson pointed out that before deviations of liquid mixtures from an ideal mixture law can be interpreted as evidence of chemical interaction or compound formation, the effects of the other possible causes of combination betwoen either similar or dissimilar molecules must be disentangled, namely, the van der Waals' cohesion forces and electrical coupling between polar molecules. In each of these alternatives as in chemical combination we have also to contemplate the reverse process of dissociation. In actual fact van der Waals' cohesion is present in every mixture of any two liquids. Electrical coupling between polar molecules occurs in all mixtures except the 'normal' liquids. Thus where chemical combination occurs it is invariably accompanied and complicated by the other two forces.

Discussing the criteria for a normal liquid Prof. Masson pointed out the danger of assuming that those liquids are normal which when mixed together give straight line property-composition curves. The use of the Ramsay-Eotvos rule concerning surface energies, Trouton's rule concerning latent heats, and Debye's polar moments, leads to the characterisation of a normal liquid as one the molecules of which remain sufficiently independent to attract one another by no forces other than the van der Waals' cohesion which they show in the vapour state. A normal liquid thus has the characteristics of a non-polar but imperfect gas. For properties such as specific volume, viscosity, vapour pressure and heats of mixing, all of which are strongly influenced by cohesion and give 